\title{
Research Article \\ Screen Bowl Centrifuge Dewatering Process: A Parameteric Study
}

\begin{abstract}
Manoj K. Mohanty
Received 7 December 2006; Accepted 6 June 2007

Recommended by Wallace Leung

Screen bowl centrifugation process is widely used for fine coal dewatering due to its relatively low cost, high capacity of providing low-moisture content product as well as relative ease of operation and maintenance. However, screen bowl centrifuge tends to lose a significant amount of ultrafine clean coal to the main effluent and screen-drain streams. This study aims at obtaining a better understanding of the parameter main effects and interaction effects with an ultimate goal of improving the dewatering performance of a screen bowl centrifuge. A three-level factorial experimental design has been utilized to conduct a test program using a continuously operated screen bowl centrifuge having a bowl diameter of 0.5 meter. The results of this study indicate that moisture content of the clean coal product is affected by both feed solid content and the pool depth maintained in the centrifuge. On the other hand, clean coal recovery to the product launder was found to be a function of feed solid content and volumetric feed flow rate but independent of the pool depth. The interaction effect of feed flow rate and feed solid content also appeared to have a significant effect on the clean coal recovery.
\end{abstract}

Copyright (C) 2007 Manoj K. Mohanty. This is an open access article distributed under the Creative Commons Attribution License, which permits unrestricted use, distribution, and reproduction in any medium, provided the original work is properly cited.

\section{INTRODUCTION}

Cleaning of fine coal, that is, coal finer than 150 microns, is yet to be a common practice in many coal preparation plants. More than half of the coal preparation plants cleaning runof-mine coals in the United States continue to directly discard the minus 150-micron-size coal fraction without any attempt to recover the clean coal present in this size fraction [1]. One of the main reasons behind the indifference of the coal operators towards fine coal cleaning is the difficulty associated with dewatering fine clean coal concentrate.

Filtration and centrifugation are the two processes most commonly used for dewatering fine clean coal. However, filtration processes are more cost intensive [2,3]. Filtration dewatering processes are also more dependent on a variety of coal characteristics including volatile matter content, inherent moisture content, and surface zeta potential, which have minimal effect on the centrifugation process [4]. Thus, developing one effective dewatering strategy applicable to a variety of coal types may be easier using a centrifugation process than the filtration systems. In addition, the screen bowl dewatering process is well accepted by many coal preparation plants due to its relative ease of operation and maintenance, low operating and capital cost, and high capacity of producing low-moisture content product. Several compar- ative studies conducted in the past using North American coal and British coal have reported the achievement of 4 to 6 percentage points lower moisture content from the screen bowl centrifuge in comparison to that of disc and drum filters $[5,6]$.

In a screen bowl centrifuge study, Gallagher et al. [7] generated useful information on performance trends as a function of key operating variable for both pilot-scale and fullsize screen bowl centrifuge. The website of Decanter Machines Inc. [8] provides a good overview of general performance trend of a screen bowl centrifuge as a function of key operating variables. In another study, Meyers et al. [9] reported solid partitioning in screen bowl centrifuge. However, none of these studies provides any insight into the parameter interaction effects of a screen bowl centrifuge. It is well known that the screen section of the screen bowl centrifuge enables it to produce a very low-moisture content product by forcing the residual water out of the thickened solid exiting from the solid-section of the centrifuge. However, it is well recognized that a significant amount of fine particles are also lost through the screen openings. The screen-drain stream having a relatively high proportion of clean coal is conventionally recirculated back to the screen bowl feed stream in many coal preparation plants to prevent the excessive loss of fine clean coal through the screen section of the centrifuge. 
However, it may be noted that such alternative effectively reduces the fresh feed treating capacity of the screen bowl centrifuge.

The Granuflow process, developed in the early 1990's, was very effective in increasing the clean coal recovery from a screen bowl centrifuge to nearly $95 \%$ while maintaining the low-moisture content of the product [10-12]. This process involved pre-conditioning of the dewatering feed slurry with bitumen emulsion to granulate the fine coal particles and minimize their loss during dewatering. However, the process has yet to prove its economic viability due to the additional cost of bitumen emulsion.

The main objective of this study was to obtain a better understanding of screen bowl process parameters and their individual as well as combined effect on the clean coal recovery and product moisture content achieved from the screen bowl centrifuge. A statistically designed experimental program was conducted to analyze the parameter main effects and interaction effects on the dewatering performance of a screen bowl centrifuge. The authors believe that such understanding is essential to achieve the maximum benefit from the screen bowl centrifuge, which is so widely used in coal preparation plants in the US.

\section{EXPERIMENTAL}

\subsection{Sample}

A coal slurry sample was collected in bulk quantity from the feed stream of raw coal classifying cyclones of coal preparation plant operating in the Midwestern US. The raw coal sample was of nominally minus $1 \mathrm{~mm}$ particle size, which was screened at 75 microns using a gyratory screen to prepare the feed slurry for the screen bowl experimental program. A relatively high feed rate was maintained while screening the screen bowl feed materials to achieve a low screening efficiency since it was desired not to completely remove all undersized particles from the oversize product. As indicated in the size distribution of Table 1, the dewatering feed material utilized in the screen bowl parametric study contained nearly $28 \%$ of minus 45 -micron-size particles.

\subsection{Screen bowl centrifuge}

The screen bowl type of centrifuge consists of a rotating cylindro-conical bowl having both solid and perforated sections, as shown in Figure 1. This is a countercurrent flow design, in which feed slurry is introduced at the conical section of the bowl through a cantilevered feed pipe. The primary solid-liquid separation takes place at the solid section of the bowl. Under the action of high centrifugal force in the range of 500 to $900 \mathrm{G}$-force [13], the solid particles tend to settle on the inside wall of the bowl, whereas the separated water flows towards the large diameter end of the bowl and is discharged as the effluent stream. The thickened solid is moved counter-current to the effluent water (or centrate) by a helical conveyor towards the screen section of the bowl. This thickened solid form a filtration bed on the screen section, which facilitates the final dewatering of the solid material al-
TABLE 1: The particle size distribution and the corresponding ash and sulfur contents for each size fraction of the original dewatering feed slurry sample used in the parametric study.

\begin{tabular}{cccc}
\hline $\begin{array}{l}\text { Size fraction } \\
(\text { micron})\end{array}$ & Weight $(\%)$ & Ash content $(\%)$ & $\begin{array}{l}\text { Sulfur content } \\
(\%)\end{array}$ \\
\hline+600 & 37.6 & 7.50 & 2.70 \\
$600 \times 150$ & 23.1 & 10.9 & 2.90 \\
$150 \times 45$ & 11.9 & 21.5 & 4.00 \\
$45 \times 11$ & 7.40 & 61.4 & 4.30 \\
-11 & 20.0 & 61.4 & 4.30 \\
\hline Total & 100.0 & 24.7 & 3.30 \\
\hline
\end{tabular}

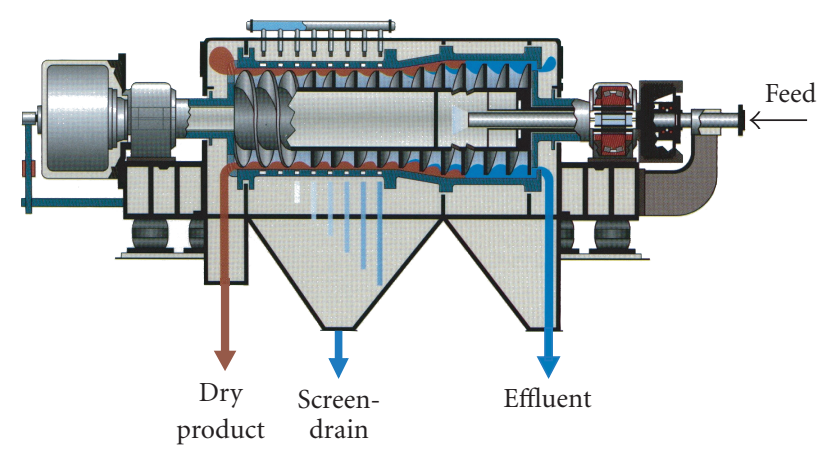

Figure 1: A schematic diagram of a screen bowl centrifuge [8].

lowing most of the residual water to drain through the screen openings. Clearly, the centrifugal sedimentation and filtration mechanisms are both utilized in the screen bowl centrifuge to dewater fine coals and thus screen bowl centrifuge is rightly described as solid bowl clarifier with a centrifugal filtration section [14].

The centrate effluent water overflows the plate dams placed at the large end of the bowl to regulate the height of the pool depth in order to control the product moisture content and also adjust the solid content of the effluent stream.

\subsection{Experimental layout and procedure}

The experimental layout used to conduct the screen bowl test program included a continuously operating $0.5 \mathrm{~m}$ diameter screen bowl centrifuge, two pumps, a 4000-liter capacity feed sump, an intermediate tank, and a product collection tank, as shown in Figure 2. Prior to the beginning of experiments, several barrels of the coal slurry sample were well mixed in the feed sump shown in the experimental layout in Figure 2. The feed slurry was pumped to an intermediate tank to be gravity-fed to the screen bowl centrifuge at a desired flow rate monitored by an online magnetic slurry-flow meter. The samples of feed slurry, dry coal product, main effluent, and screen-drain were collected for each test. All product streams were mixed together in the product collection tank and recirculated to the feed tank to perform a large number of tests using a limited amount of slurry samples. Since, significant particle size degradation was expected from screen 


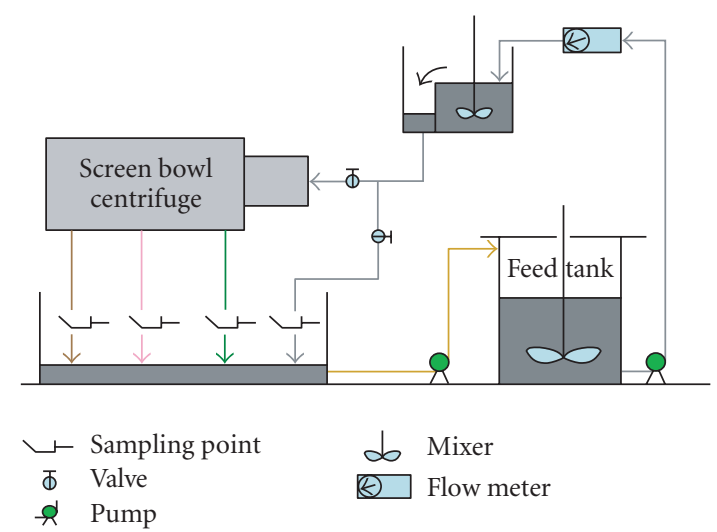

Figure 2: A schematic layout of the experimental circuit used in this study.

bowl centrifuging over a long period, the slurry samples were introduced to the centrifuge after adjusting all the operating parameters only for a few minutes required for the collection of samples from the three product streams. During rest of the experimental period, the feed slurry was merely recirculated in the circuit to keep the solids in suspension, as shown in Figure 2.

This experimental study concentrated on investigating the parametric effects on the performance of the screen bowl centrifuge by using a feed slurry prepared by screening at 75 microns. A total of 17 experiments were conducted using a factorially designed experimental program to investigate the main and interaction effects of feed volumetric flow rate, feed solids content, and the pool depth on the dewatering performance. A completely randomized test matrix was developed using the Design Expert statistical software package by varying the three process parameters in the range of $75 \mathrm{lpm}$ to $190 \mathrm{lpm}, 9 \%$ to $27 \%$, and 0 to $3.81 \mathrm{~cm}$, respectively. The complete test matrix, showing the operating condition for each test is shown in Table 2. The rotational speed of the screen bowl was maintained at the manufacturer's recommended level of $1400 \mathrm{rpm}$ during the entire experimental program to produce a centrifugal field of nearly $500 \mathrm{G}$-force.

\section{RESULTS AND DISCUSSION}

One of the main objectives of this study was to conduct a statistically designed parametric study to obtain a better understanding of the main effects and interaction effects of the key process parameters on the performance of a screen bowl centrifuge. Maximizing the recovery of clean coal to the dry product stream of the centrifuge and minimizing the product moisture content were of critical importance to this investigation. Empirical model equations were developed to describe clean coal recovery to product, screen-drain, and the main effluent streams along with product moisture content as functions of the key process parameters. The models were simulated by systematically varying desired process parameters to study their main and interaction effects on the aforementioned four process responses.
The parametric study was conducted using a BoxBehnken experimental design matrix to study not only the parameter main effects but also their interaction effects on the dewatering performance of the screen bowl centrifuge. A detailed list of individual test conditions and the results produced is provided in Table 2. These test data were statistically analyzed using a commercially available software package, known as the Design Expert. Empirical model equations were developed using the stepwise regression approach for all four process responses. Several type of model equations were investigated and finally the equations with the highest adjusted $R^{2}$ (coefficient of determination) values were selected for the aforementioned dewatering responses. The individual model equations are described as follows:

$$
\begin{aligned}
& \text { Product moisture }(\%) \\
& \quad=6.40+0.17 \mathrm{FS}+1.34 \mathrm{PD}-0.44 \mathrm{PD}^{2} \\
& \text { Product clean coal recovery }(\%) \\
& \quad=42.7+0.142 \mathrm{FR}+5.07 \mathrm{FS}-0.15 \mathrm{FS}^{2}-0.007 \mathrm{FR}^{*} \mathrm{FS}
\end{aligned}
$$

Effluent clean coal recovery (\%)

$$
\begin{aligned}
= & 4.31-0.02 \mathrm{FR}+0.15 \mathrm{FS}-0.12 \mathrm{PD} \\
& +0.32 \mathrm{PD}^{2}-0.11 \mathrm{FS}^{*} \mathrm{PD} .
\end{aligned}
$$

Screen-drain recovery $(\%)$

$$
\begin{aligned}
= & 62.41-0.20 \mathrm{FR}-5.86 \mathrm{FS}-3.06 \mathrm{PD}+0.16 \mathrm{FS}^{2} \\
& +0.009 \mathrm{FR}^{*} \mathrm{FS}+0.23 \mathrm{FS}{ }^{*} \mathrm{PD},
\end{aligned}
$$

where FS is feed solid content in \% by weight, PD is pool depth in $\mathrm{cm}$, and FR is feed flow rate in liters per minute (lpm). The comparison between the actual experimental data points and the values predicted using the model equations are illustrated in Figures 3(a), 3(b), 3(c), and 3(d).

As shown, the predicted values compared satisfactorily with the actual experimental data for all responses with the exception of product moisture response. The scatter in the product moisture data shown in Figure 3(a) was quite high, which is also evident from the relatively inferior $R^{2}$ value of 0.54 of the corresponding regression fit. During the dewatering experiments, it was observed that the temperature of the coal slurry was slightly raised due to its continuous recirculation over a period of time. In other words, the slurry temperature was not constant from test to test. Based on the findings from a recent study [15], slurry temperature does play a role in the moisture content of the dewatered product. This phenomenon may have contributed to the scatter in the product moisture data and relatively poor $R^{2}$ value. The scatter in the data for the other three responses were minimal; this fact is also apparent from the high $R^{2}$ values of 0.94 , 0.85 , and 0.93 of the regression fits for clean coal recovery to the product, effluent and screen-drain streams, respectively. The predicted $R^{2}$ values were in reasonable agreement for all models. The lack of fit component was not significant for any of the regression fits.

It was desired to investigate the behavior of the screen bowl centrifuge to the simultaneously changing operating parameters utilizing the aforementioned empirical model 
TABLE 2: A list of operating parameter values used and the screen bowl dewatering performance data obtained from the parametric study conducted as a part of this investigation.

\begin{tabular}{c|c|c|c|c}
\hline \multicolumn{5}{c}{ Operating parameter values } \\
\hline Test no. & Feed flow $(\mathrm{lpm})$ & Bowl speed (rpm) & Pool depth (cm) \\
\hline 1 & 132.5 & 18.0 & 1400 & 1.91 \\
2 & 190 & 18.0 & 1400 & 0 \\
3 & 75 & 18.0 & 1400 & 0 \\
4 & 75 & 18.0 & 1400 & 1.91 \\
5 & 132.5 & 18.0 & 1400 & 1.91 \\
6 & 75 & 27.0 & 1400 & 3.81 \\
7 & 190 & 18.0 & 1400 & 0 \\
8 & 132.5 & 9.0 & 1400 & 0 \\
9 & 132.5 & 27.0 & 1400 & 1400 \\
10 & 132.5 & 18.0 & 1400 & 1.91 \\
11 & 75 & 9.0 & 1400 & 1.91 \\
12 & 132.5 & 18.0 & 1400 & 1.91 \\
13 & 190 & 9.0 & 1400 & 1.91 \\
14 & 132.5 & 9.0 & 1400 & 3.81 \\
15 & 132.5 & 18.0 & 1400 & 1.91 \\
17 & 132.5 & 27.0 & 1400 & 3.81 \\
\end{tabular}

\begin{tabular}{c|c|c|c|c}
\hline \multicolumn{5}{c}{ Results } \\
\hline \multirow{2}{*}{ Test no. } & Product moisture (\%) & \multicolumn{3}{|c}{ Clean coal recovery (\%) } \\
\cline { 2 - 4 } & 15.5 & Product & Effluent & Screen-drain \\
\hline 1 & 9.2 & 85.7 & 5.30 & 8.96 \\
2 & 8.4 & 87.6 & 11.1 & 1.26 \\
3 & 82.7 & 5.58 & 11.7 \\
4 & 11.0 & 84.1 & 7.15 & 8.41 \\
5 & 11.7 & 88.8 & 6.74 & 4.51 \\
6 & 13.3 & 67.9 & 6.33 & 25.8 \\
7 & 7.4 & 91.6 & 8.05 & 0.38 \\
8 & 7.5 & 85.3 & 9.04 & 5.62 \\
9 & 10.1 & 66.6 & 11.4 & 22.0 \\
10 & 8.3 & 84.4 & 5.80 & 9.76 \\
11 & 9.5 & 84.7 & 6.67 & 8.68 \\
12 & 8.2 & 92.1 & 6.66 & 1.63 \\
13 & 9.5 & 90.6 & 8.48 & 1.07 \\
14 & 6.0 & 87.1 & 7.80 & 5.09 \\
15 & 12.5 & 92.0 & 6.75 & 1.26 \\
16 & 11.0 & 60.2 & 2.31 & 37.5 \\
17 & 10.3 & 60.2 & 2.20 & 37.6 \\
\hline
\end{tabular}

equations. Equation (1) indicates the significant contribution of feed solids content and pool depth in influencing the moisture content of the screen bowl product. The linear relationship of the product moisture content with the feed solids content and the quadratic relationships with the pool depth are also illustrated graphically in Figures 4(a) and 4(b). At lower feed solid content, solid-liquid separation inside the bowl takes place in more of a free settling environment; whereas higher feed solid content creates more of a hindered settling type of separation environment inside the bowl. In spite of the relatively high centrifugal field of nearly
$500 \mathrm{G}$ maintained inside the centrifuge, it appears that the hindered settling environment results in more residual moisture in the thickened solid bed leaving the solid section and entering the screen section of the bowl. The higher moisture content of the thickened solids entering the screen section results in relatively high moisture content of the product leaving the screen section and being discharged at the product launder.

On the other hand, the increase in pool depth by increasing the height of the plate dam restricts the discharge of effluent water. This effectively allows more amount of 


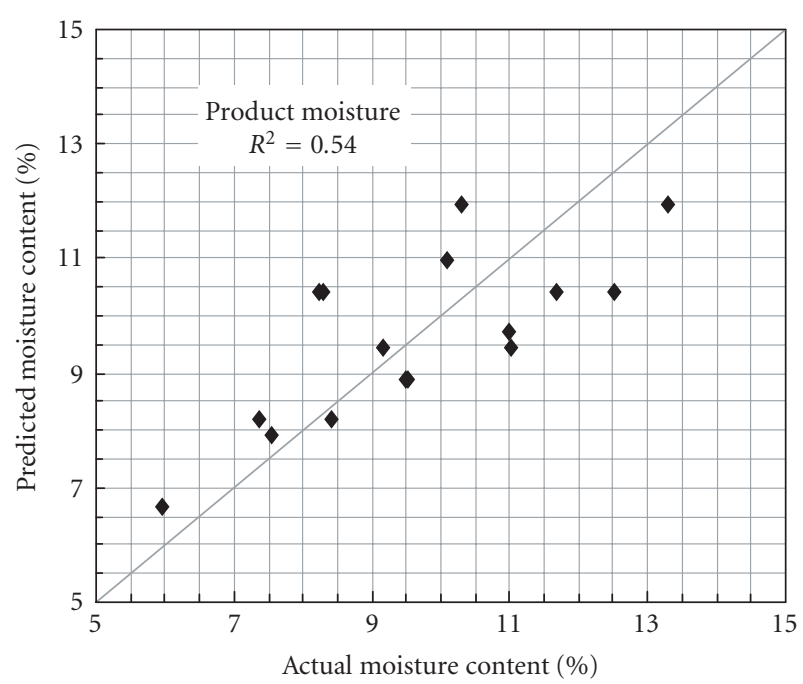

(a)

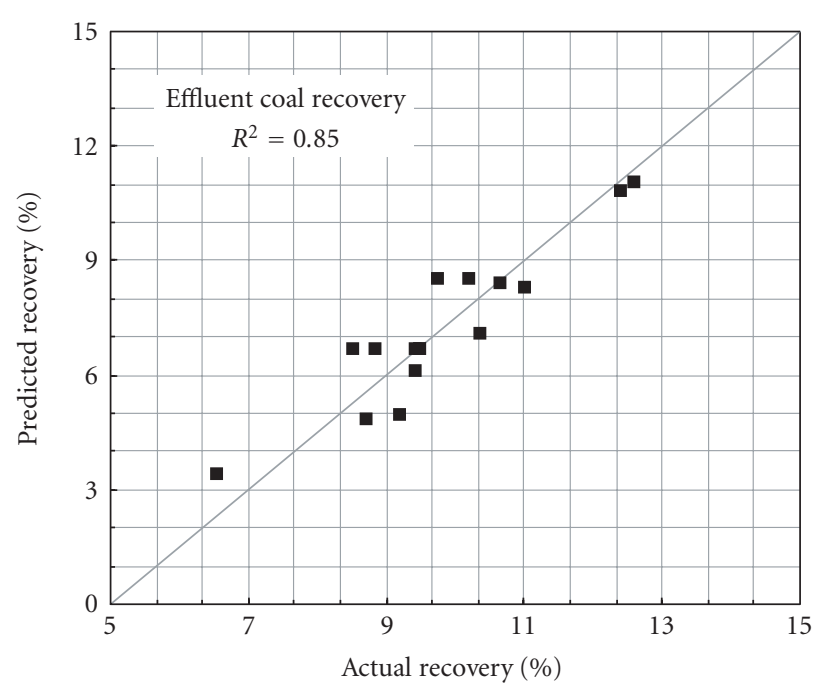

(c)

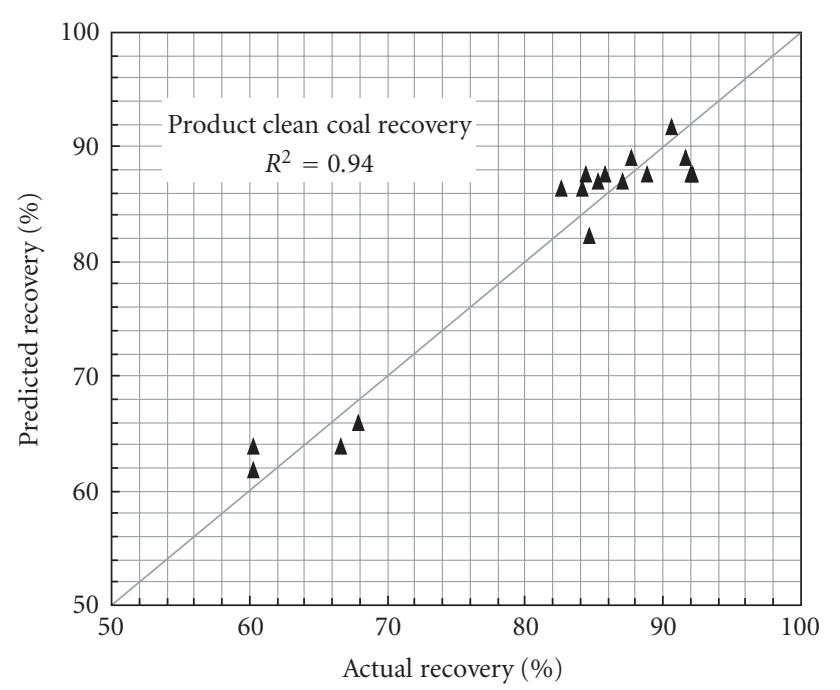

(b)

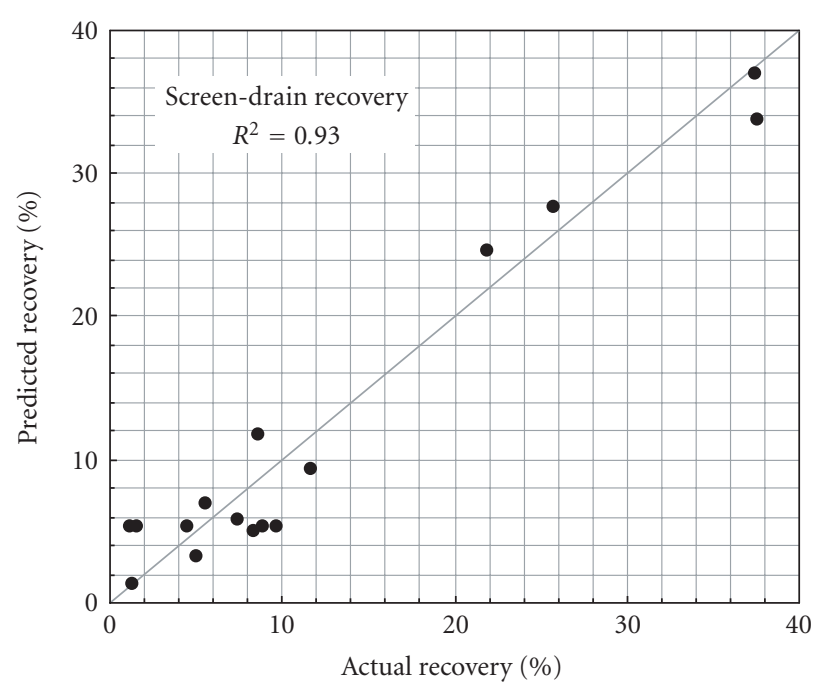

(d)

FIgURE 3: Comparison of experimental data and the predicted data generated from the individual model equation for various dewatering performance responses.

water to remain in the thickened solid, which exits from the solid section and enters the screen section of the bowl. This phenomenon ultimately results in an increased moisture content of the clean coal product being discharged at the product launder.

As indicated in equation (2), the pool depth does not appear to have any effect on the clean coal recovery to the product stream of the screen bowl centrifuge. Feed solid content contributes the most towards the clean coal recovery followed by the volumetric feed flow rate, as illustrated in Figures 5(a) and 5(b). It is believed that with the increasing feed solids content from $9 \%$ up to $15 \%$, the thickness of the solid filtration bed on the screen section gradually increases thus decreasing the permeability. This reduces the loss of solid particles through the screen section of the bowl thus improving the clean coal recovery to the product stream.
This hypothesis is also supported by the discussion on the screen-drain recovery provided in a subsequent section. Beyond an optimum solid content of nearly $15 \%$, the increased feed solid content results in more of a hindered settling environment inside the bowl as described in the aforementioned section. Within a limited retention time, the fine particles tend not to settle and thus are carried over to the centrate with the effluent water. This results in the loss of increasing amount of clean coal through the effluent stream and a commensurate reduction in clean coal recovery to the product stream. This hypothesis is also supported by the findings on the effluent recovery discussed in a subsequent section.

As illustrated in Figure 5(a), this effect is more pronounced at higher volumetric feed flow rate than at lower feed rate due to the reduced residence time of the feed slurry inside the bowl in the former case. Increasing volumetric 


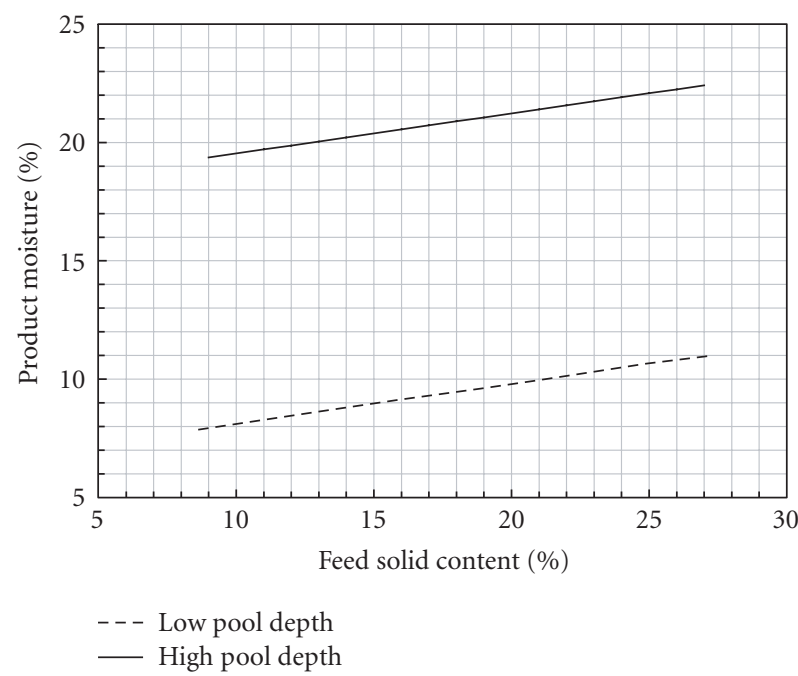

(a)

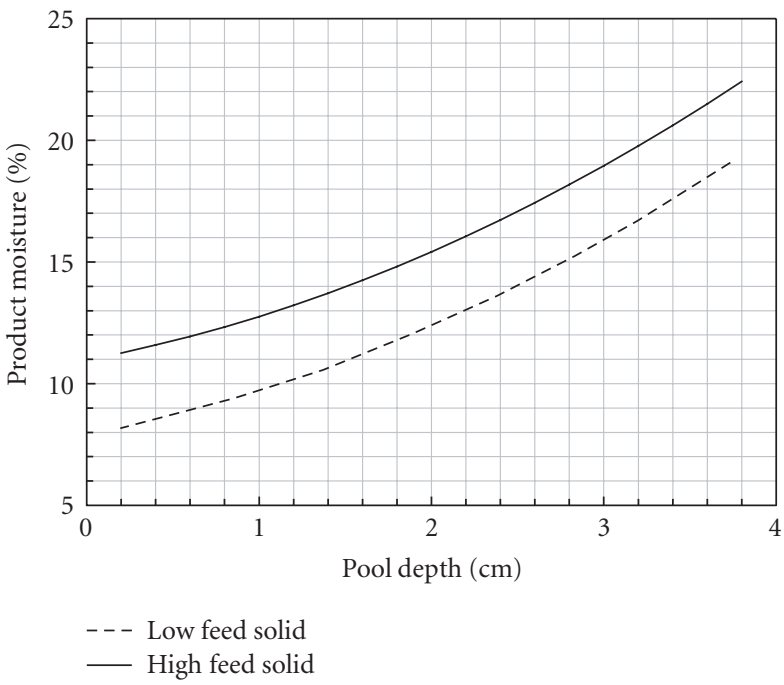

(b)

FIGURE 4: Illustration of the parametric effects on the moisture content of the dewatered product of a screen bowl centrifuge.

flow rates exhibit similar effect on clean coal recovery to the product, as illustrated in Figure 5(b). At low feed solid content, the clean coal recovery shows an upward trend apparently due to the reduced permeability and increased resistance of a thicker solid filtration bed on the screen section of the bowl with an increase in volumetric feed rate. However, at the high level of feed solid content, increasing amounts of clean coal particles are lost to the centrate along with the effluent water due to the combined effect of a hindered settling environment inside the bowl and a decrease in slurry retention time caused by an increasing volumetric flow rate. This phenomenon causes the reduction in clean coal recovery at high feed solid content, as illustrated in Figure 5(b).

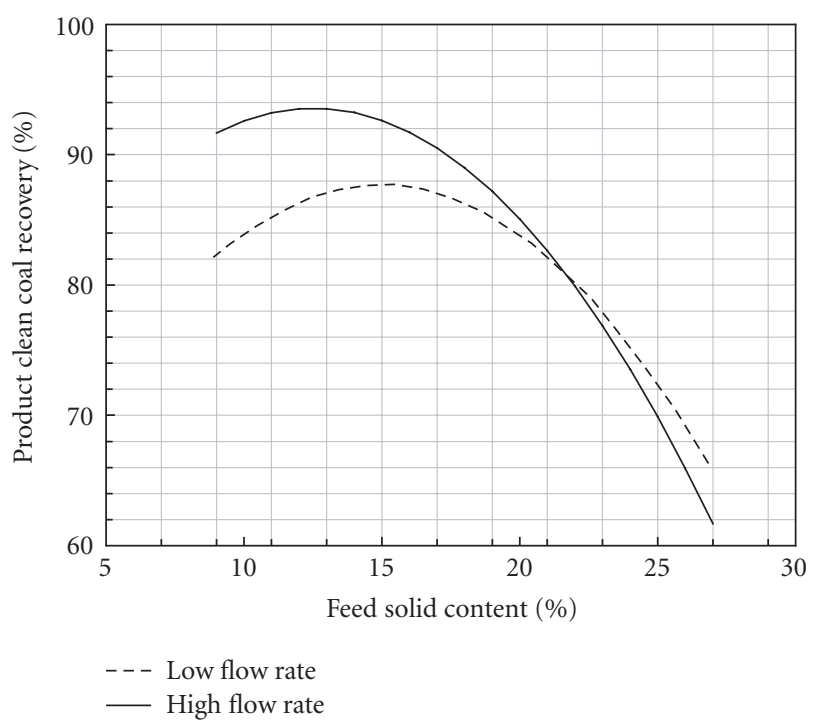

(a)

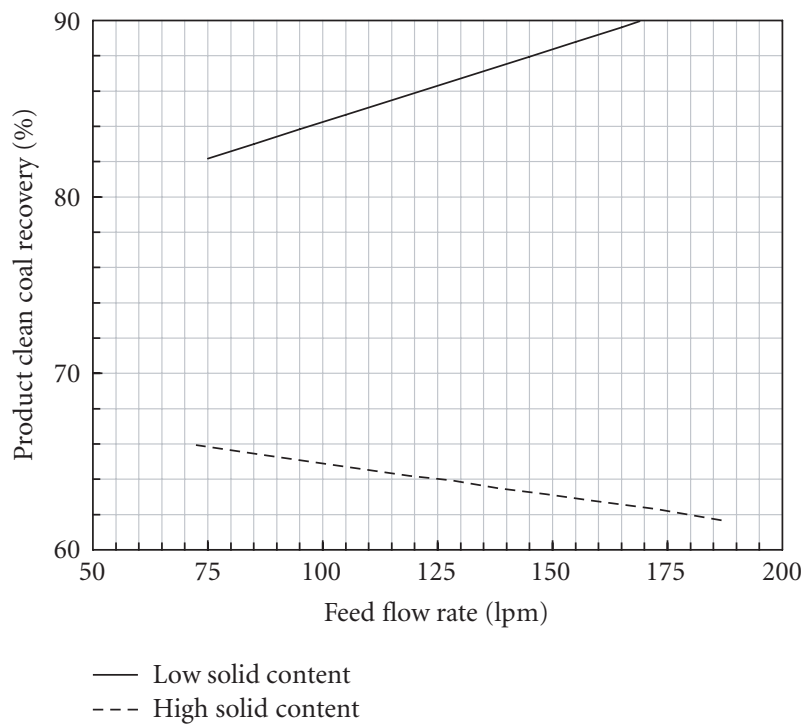

(b)

Figure 5: Parametric effects on the clean coal recovery to the product stream of a screen bowl centrifuge.

Equation (3) as well as Figures 6(a) and 6(b) illustrate the effect of key process parameters such as pool depth, feed solids content, and volumetric feed flow rate on the clean coal loss through the main effluent stream. The interaction effect of feed solids content and pool depth on the clean coal loss is clearly evident from Figure 6(a), which means the plate-dam height needs to be adjusted to maintain the same level of clean coal loss at various levels of feed solids content. However, no such interaction between feed solid content and volumetric feed flow rate is evident from the plot in Figure 6(b). As indicated, the clean coal loss at low feed solid content is slightly higher than at high feed solid content. In screen bowl dewatering process, a majority of the 


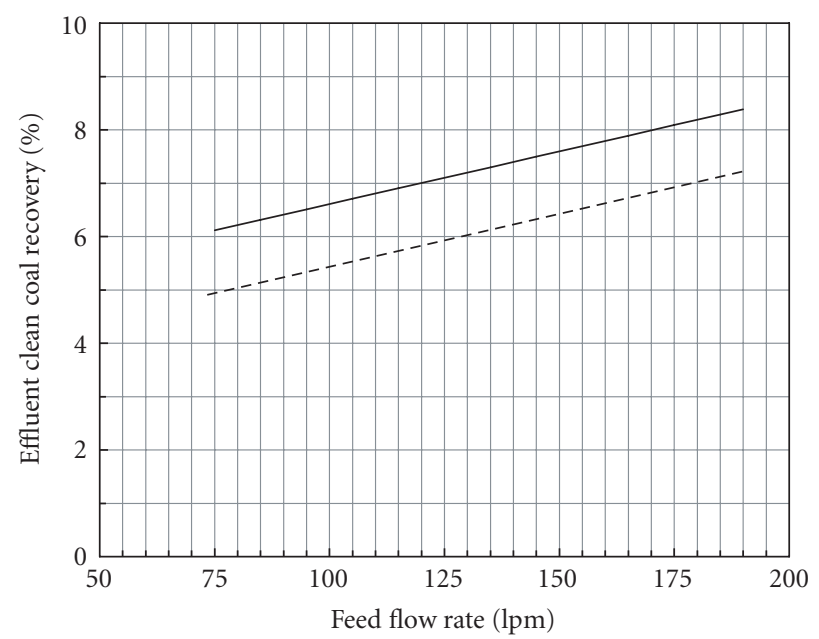

_ Low feed solid

- - - High feed solid

(a)

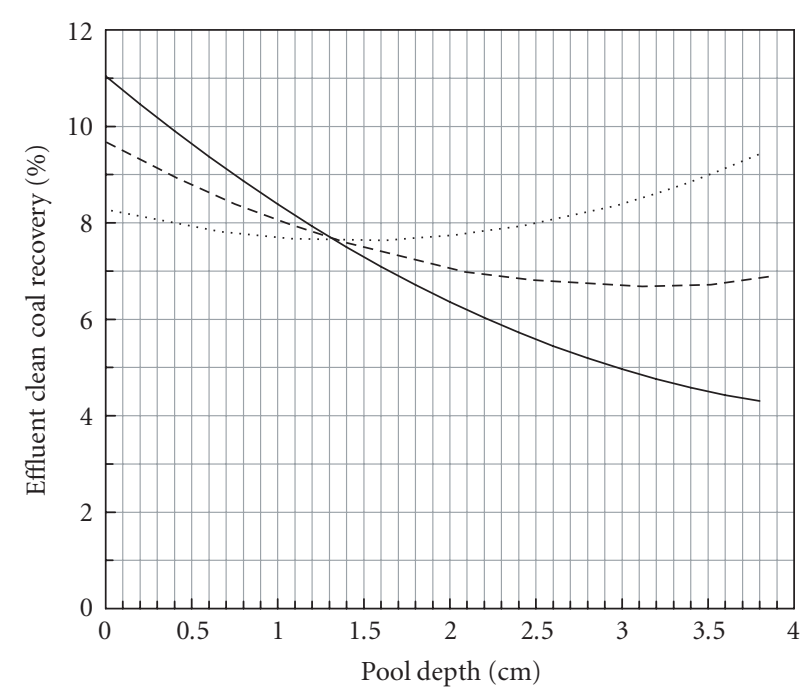

..... Low feed solid

— High feed solid

- - - Medium feed solid

(b)

Figure 6: Effects of the process parameters on the loss of clean coal through the effluent stream of a screen bowl centrifuge.

water reports to the centrate; this means, the amount of water recovered to the effluent stream is more with low solids content feed slurry due to its higher water content.

The increase in clean coal loss occurring due to an increase in the volumetric feed flow rate may be caused by the concomitant increase in the rate of effluent water. The greater rate of effluent water is believed to carry over greater amount of entrained ultrafine fine clean coal particles causing a greater loss of clean coal.

Figures $7(a)-7(c)$ and equation (4) describe the influence of key process parameters on the recovery (or loss) of clean

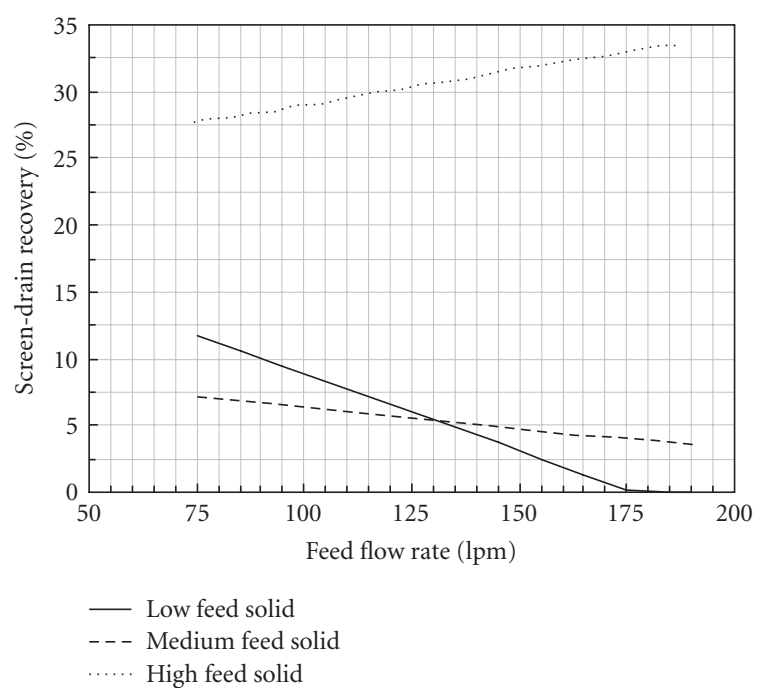

(a)

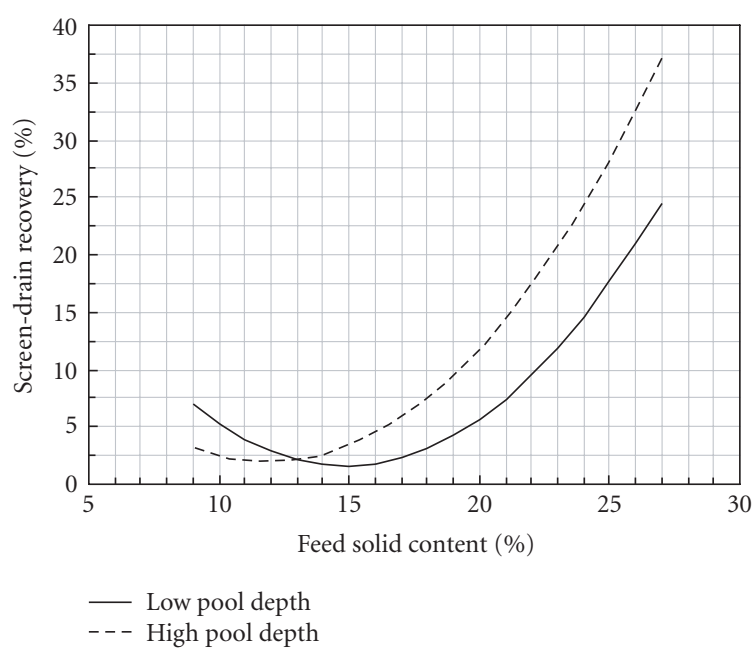

(b)

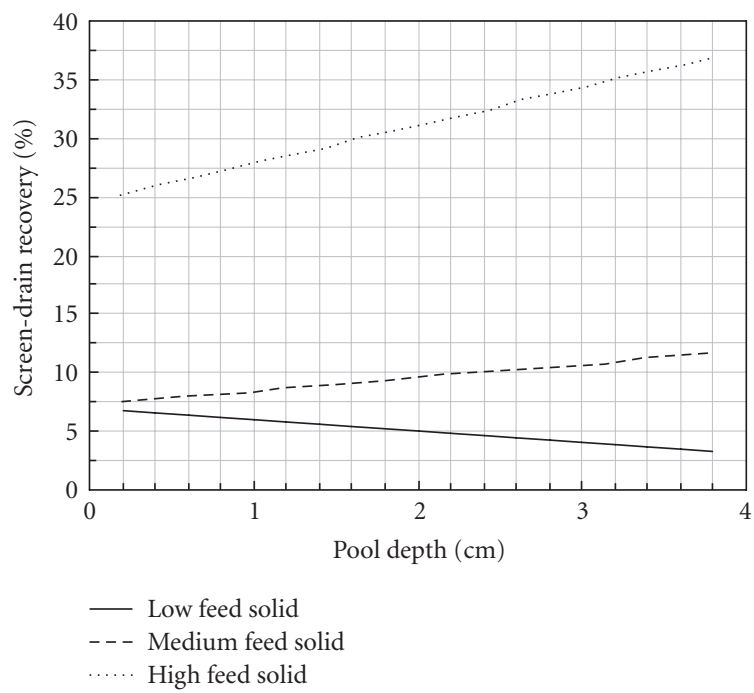

(c)

Figure 7: Effects of the process parameters on the loss of clean coal through the screen-drain stream of a screen bowl centrifuge. 
coal to the screen-drain. The interaction effects of feed solid content versus feed flow rate as well as feed solid content versus pool depth appear to have significant effect on the clean coal recovery to the screen-drain. At low and medium levels of feed solid content, an increasing feed flow rate allows the creation of a thicker solid bed having lower permeability, which causes a gradual reduction in the clean coal recovery to the screen-drain streams. On the other hand, at higher level of feed solid content, the hindered settling environment as well as the decreasing slurry residence time inside the bowl due to increasing volumetric flow rate prevents the formation of a consolidated material bed. The relatively loose material bed causes a significant loss of solid particles through the screen openings thus, increasing the recovery of clean coal to the screen-drain stream, as indicated in Figure 7(a).

The screen-drain recovery plotted as a function of feed solids content in Figure 7(b) supports the hypothesis stated previously while discussing the results of Figure 5(a). At the lowest level of solid content, the solid layer on the screen section is not sufficiently thick to prevent the solid particles from passing through the bed and the screen openings, thus causing a relatively high recovery of clean coal to the screendrain stream. However, with an increasing solid content, the solid bed on the screen section becomes sufficiently thick to resist the seepage of solid particles through the bed until an optimum solid content level of $12 \%$ to $15 \%$. Beyond this solid content, the greater mass of solid material in the feed slurry creates a hindered settling environment inside the centrifuge. This environment hinders the creation of a consolidated bed of solid, which when passes through the screensection gives way to a substantial amount of solid particle thus, increasing the screen-drain recovery of clean coal.

\section{CONCLUSIONS}

The important findings of this screen bowl centrifuge dewatering study conducted in a pilot-scale have been summarized in the following paragraphs.

The moisture content of the clean coal product is affected by both feed solids content and pool depth maintained in the centrifuge but not by the feed volumetric flow rate. At low feed solid content, a free settling environment created inside the centrifuge allows an adequate solid-liquid separation, which results in a low-moisture content of the clean coal product. However, the higher solid content of the feed slurry tends to create more of a hindered settling environment inside the centrifuge, which hinders a complete separation of liquid from the solid mass. This results in substantial amount of residual moisture in the solid bed, which exits from the solid section of the centrifuge. The high moisture content of the thickened solid entering the screen section results in relatively high moisture content of the clean coal product. On the other hand, the increase in pool depth by increasing the height of the plate-dam restricts the flow of water to the effluent port. This effectively allows more amount of water to remain in the thickened slurry, which exits from the solid section of the bowl. Again, the high moisture content of the thickened slurry entering the screen section results in rela- tively high moisture content of the product leaving the screen section and being discharged at the product launder.

The recovery of clean coal to the product launder is a function of feed solids content and volumetric feed flow rate but independent of the pool depth. The interaction of feed flow rate and feed solid content also appears to have a significant effect on the clean coal recovery to the product launder. The recovery of clean coal appears to maximize at a feed solids content of $12 \%$ to $15 \%$ subject to a volumetric flow rate in the range of $75 \mathrm{lpm}$ and $190 \mathrm{lpm}$ to a screen bowl centrifuge of $0.5 \mathrm{~m}$ diameter. However, it must be realized that this optimum feed solid content is appropriate for a dewatering feed having $28 \%$ of minus 45 microns particle-size solids. The optimum solid content may be higher with a reduced percentage of ultrafine (minus 45 microns) particles in the dewatering feed. Beyond this optimum solid content, the process environment inside the screen bowl becomes more of hindered settling type, which apparently prevents the formation of a consolidated solid bed within a limited residence time of the coal slurry inside the bowl. A relatively unconsolidated solid bed results in more solid losses through the effluent and screen-drain stream thus lowering the clean coal recovery to the product launder.

The clean coal loss through the effluent stream appears to be affected by all three process parameters investigated during this study. In addition, the interaction of feed solids content and pool depth also appears to contribute to the clean coal loss through the effluent stream. An increase in the feed flow rate marginally increases the loss of clean coal to the effluent stream. On the other hand, an increase in pool depth, which does not affect the clean coal recovery to the product, appears to decrease the clean coal loss to the effluent except at the lowest feed solids content of $9 \%$, where the clean coal loss remains nearly constant. In other words, it means the recovery of clean coal to the screen-drain stream also increases with an increase in pool depth at higher feed solid content.

\section{ACKNOWLEDGMENTS}

The author sincerely acknowledges the funds provided by the Illinois Clean Coal Review Board for a part of this investigation. Special thanks are extended to Mr. Rick Geilhausen, Mr. Ayan Palit, Mr. Bikash Dube, and Mr. Nitin Khanna who provided considerable help while conducting this experimental program. In addition, the author greatly appreciates the technical guidance and equipment support provided by Mr. Ken Robinette and Mr. Ron Jahnings of the Decanter Machine Inc., USA.

\section{REFERENCES}

[1] Keystone Coal Industry Manual, Published by Coal Age, 2001.

[2] B. K. Parekh and J. P. Matoney, "Mechanical dewatering," in Coal Preparation, J. W. Leonard, Ed., pp. 499-580, AIME, New York, NY, USA, 5th edition, 1991.

[3] N. C. Lockhart and C. J. Veal, "Coal dewatering: Australian R\&D trends," Coal Preparation, vol. 17, no. 1-2, pp. 5-24, 1996. 
[4] R. X. Rong and J. Hitchins, "Preliminary study of correlations between fine coal characteristics and properties and their dewatering behaviour," Minerals Engineering, vol. 8, no. 3, pp. 293-309, 1995.

[5] E. B. Wilson and F. G. Miller, "Coal dewatering-some technical and economic considerations," Mining Congress Journal, vol. 60, no. 9, pp. 116-121, 1974.

[6] R. S. Shaw, "The screen bowl centrifuge for dewatering froth floated fines," Mine and Quarry Magazine, pp. 60-64, 1980.

[7] E. L. Gallagher, J. Post, A. Swanson, and L. Armstrong, "Dewatering of fine coal by screen-bowl centrifuges," in Proceedings of the 1st Australian Coal Preparation Conference, A. R. Swanson, Ed., pp. 134-154, Newcastle, Canada, October 1981.

[8] Decanter Machine Inc., 2003, http://www.decantermachine .com/.

[9] A. D. Meyers, T. Wex, and K. R. Leach, "Solids partitioning in screen-bowl centrifuges," in Proceedings of the 9th Australian Coal Preparation Conference, B. Firth, Ed., pp. 209-221, Yeppoon, Australia, October 2002.

[10] W. W. Wen, "An integrated fine coal preparation technology: the GranuFlow process," International Journal of Mineral Processing, vol. 58, no. 1-4, pp. 253-265, 2000.

[11] W. W. Wen and R. P. Killmeyer, "Centrifugal dewatering and reconstitution of fine coal: the GranuFlow process," Coal Preparation, vol. 17, no. 1-2, pp. 89-102, 1996.

[12] W. W. Wen and A. W. Deurbouck, "Combined method of simultaneously dewatering and reconstituting finely divided carbonaceous material," US Patent No. 4, 969, 928, 1990.

[13] D. G. Osborne, Coal Preparation Technology, Kluwer Academic Publishers, Norwell, Mass, USA, 1988.

[14] N. D. Policow and J. S. Orphanos, "Development of the screen bowl centrifuge for dewatering coal fines," Mining Engineering, vol. 35, no. 4, pp. 333-336, 1983.

[15] A. Patwardhan, Y. P. Chugh, B. J. Arnold, and A. N. Terblanche, "Dewatering ultrafine clean coal," in Proceedings of the 21st International Pittsburgh Coal Conference, T. H. Filter Press, Osaka, Japan, September 2004.

\section{AUTHOR CONTACT INFORMATION}

Manoj K. Mohanty: Department of Mining and Mineral

Resources Engineering, Southern Illinois University at Carbondale, Carbondale, IL 62901-6603, USA; mohanty@engr.siu.edu 